\section{Regulation of Coronary Vasomotor Function by Reactive Oxygen Species}

\author{
Lih Kuo $^{1 *}$, Naris Thengchaisri ${ }^{1}$ and Travis W. Hein
}

\begin{abstract}
Overproduction of reactive oxygen species is closely associated with cardiovascular diseases in part by impairing endothelial function and consequently compromising blood flow regulation. Superoxide and hydrogen peroxide are elevated under various disease states with reduced endothelium-derived nitric oxide bioavailability. The oxidative stress elicited by angiotensin II, C-reactive protein and tumor necrosis factor- $\alpha$ is mediated by the activation of different redox signaling pathways in the microvasculature. The upregulation of L-arginine consuming enzyme arginase also contributes to the reduced nitric oxide bioavailability during oxidative stress. Hydrogen peroxide exhibits vasodilator function in the coronary microcirculation and plays an important role in the physiological regulation of coronary blood flow. However, excessive production of hydrogen peroxide impairs endothelial function by reducing L-arginine availability through hydroxyl radical-mediated upregulation of arginase. This review summarizes the current knowledge on the effects superoxide and hydrogen peroxide on vasomotor function regulated by the endothelium-derived nitric oxide and prostacyclin in the coronary microcirculation.
\end{abstract}

\section{Keywords: Oxidative stress; Microcirculation; Endothelium}

A normal function of vascular endothelium, responding to physical [1], chemical [2,3], and electrical [4,5] stimuli, is essential to maintain microvascular homeostasis and regulate local blood flow by changing vasomotor tone via release of endothelium-derived vasodilators (e.g., nitric oxide, prostacyclin, C-type natriuretic peptide and hyperpolarizing factors) and vasoconstrictors (e.g., endothelin, prostaglandin $\mathrm{H} / \mathrm{F}$, thromboxane and angiotensin). Endothelial dysfunction is one of the earliest markers of vascular abnormalities observed in many cardiovascular diseases associated with oxidative stress due to excessive production of reactive oxygen species (ROS). Redox regulation of proteins by moderate levels of ROS is indispensable for signaling pathways underlying the regulation of subcellular and cellular activity as well as cardiovascular function [6-8]. Superoxide is produced by several enzyme systems in the cell and it is converted to hydrogen peroxide $\left(\mathrm{H}_{2} \mathrm{O}_{2}\right)$ by superoxide dismutase. $\mathrm{H}_{2} \mathrm{O}_{2}$ itself is a potent oxidizing agent

\footnotetext{
${ }^{*}$ Corresponding author: Lih Kuo, Professor and Kruse Family Centennia Chair, Department of Systems Biology and Translational Medicine, College of Medicine, Texas A\&M Health Science Center, 702 Southwest H.K. Dodgen Loop, Temple, Texas 76504, USA, Tel: 254-742-7032; Fax: 254-742-7145; E-mail: LKUO@tamhsc.edu
}

Received: July 14, 2012 Accepted: July 30, 2012 Published: August 08, 2012 that can be converted to hydroxyl radical in the presence of ferric compounds. $\mathrm{H}_{2} \mathrm{O}_{2}$ can be degraded by catalase to form $\mathrm{H}_{2} \mathrm{O}$ and an oxygen molecule. Among the aforementioned ROS, superoxide and $\mathrm{H}_{2} \mathrm{O}_{2}$ are the most common and important molecules involved in the physiological and pathophysiological events [7,8]. Compared with superoxide, $\mathrm{H}_{2} \mathrm{O}_{2}$ is stable, lacks charge, has longer half-life, is cell permeable and can diffuse across longer distances. Therefore, its physical properties are suitable for second-messenger signaling $[7,8]$. Since a proper delivery of oxygen and nutrients to the tissue is essential for the normal function of an organ, in this brief review we will discuss the role of superoxide and $\mathrm{H}_{2} \mathrm{O}_{2}$ in the physiological/ pathophysiological regulation of vasomotor activity of resistance arterioles in the microvascular beds where blood flow is primarily controlled, with special focus on the coronary microcirculation.

The elevated level of superoxide and $\mathrm{H}_{2} \mathrm{O}_{2}$ has been detected under various pathophysiological conditions, including ischemiareperfusion, inflammation, hypertension, diabetes, and atherosclerosis. All of these conditions have been reportedly associated with endothelial dysfunction with reduced NO bioavailability. In animal models of hypertension and myocardial hypertrophy, the excessive ROS release associated with renin-angiotensin system activation has been well documented $[9,10]$. However, the vasomotor action of angiotensin II (AngII) in the coronary circulation is controversial in view that coronary blood flow can be reduced or increased by AngII $[11,12]$. It is also unclear whether AngII can modulate vascular tone by generating ROS since enhanced superoxide production by AngII has been reported [13]. Using isolated vessel approaches to eliminate the confounding influences from systemic and local effects inherited in in-vivo preparations, we found that AngII evokes a moderate vasoconstriction of coronary arterioles $(50-80 \mu \mathrm{m}$ in diameter) at low concentrations $(\sim 1 \mathrm{nmol} / \mathrm{L})$ but a marked vasodilation at higher concentrations $(>10 \mathrm{nmol} / \mathrm{L})$ [14]. This concentration-dependent vasomotor reaction to AngII may explain the inconsistent coronary flow changes observed in in-vivo conditions. Interestingly, pretreating the isolated coronary arterioles with a sub-vasomotor concentration of AngII $(0.1 \mathrm{nmol} / \mathrm{L})$ for 60 minutes caused an elevation of superoxide production in the vascular wall and inhibited NO production and endothelium-dependent, NO-mediated dilation in response to adenosine, a potent metabolic vasodilator in the heart. This inhibitory effect of AngII was prevented by AngII type 1 receptor (AT1) blocker losartan, superoxide scavenger TEMPOL, or NAD(P) $\mathrm{H}$ oxidase inhibitor apocynin [14]. These microvascular findings indicate that AngII, at the level without causing vasomotor activity, exerts an adverse effect on endothelium-dependent NO-mediated vasodilator function via released superoxide through AT1-mediated activation of the $\mathrm{NAD}(\mathrm{P}) \mathrm{H}$ oxidase pathway. It is speculated that the small elevation of local AngII in the heart during disease states may cause local endothelial dysfunction and subsequently elicit focal vasoconstriction and myocardial ischemia. Moreover, the increase of coronary flow, i.e., vasodilation of resistance arterioles, in response to metabolic stress might be compromised if the global level of AngII is slightly elevated in the heart. The inflammatory marker C-reactive 
protein (CRP), which is now established as a cardiovascular risk factor, also exhibits similar adverse effects on endothelium-dependent NO-mediated vasodilatory function and NO production in both coronary [15] and retinal [16] arterioles by enhancing NAD(P)H oxidase-mediated superoxide production in the vascular wall via p38 kinase activation. The CRP also affects endothelial arachidonic acid-prostanoid pathways [17]. The formation of peroxynitrite from NO (basal release) and superoxide (CRP-stimulated release) in the endothelium appears to compromise prostacyclin $\left(\mathrm{PGI}_{2}\right)$ production, and thus $\mathrm{PGI}_{2}$-mediated vasodilation, by inhibiting $\mathrm{PGI}_{2}$ synthase activity through tyrosine nitration [17]. Peroxynitrite also contributes to endothelial NO synthase (eNOS) uncoupling by oxidizing the cofactor $\mathrm{BH}_{4}[18]$ and thus reduces $\mathrm{NO}$ production.

Tumor necrosis factor- $\alpha$ (TNF- $\alpha$ ) is a proinflammatory cytokine and an important mediator of cardiovascular complications such as acute myocardial infarction, ischemia-reperfusion injury, atherosclerosis, chronic heart failure and coronary arterial disease in association with diminished coronary blood flow. Treating the isolated coronary arterioles with a pathological concentration of TNF- $\alpha$ ( $1 \mathrm{ng} / \mathrm{ml}, 90$ minutes) caused a significant reduction of NO release, enhanced superoxide production and JNK phosphorylation in arteriolar endothelial cells and impaired endothelium-dependent dilation to adenosine [19]. In contrast with the insults elicited by AngII and CRP, the TNF- $\alpha$ induced oxidative stress and endothelial dysfunction are associated with the activation of ceramide-induced activation of JNK and subsequent production of superoxide via xanthine oxidase $[19,20]$. In the model of ischemia-reperfusion injury of coronary arterioles, the endothelial dysfunction in relation to NO deficiency is likely related to the upregulation of arginase-I [21], an enzyme that competes with eNOS for their common substrate $\mathrm{L}$-arginine. Interestingly, the upregulated arginase-I in the vascular wall also contributes, in part, to the reduced NO production and impaired endothelium-dependent dilation in coronary arterioles challenged with oxidized low-density lipoproteins [22].

$\mathrm{H}_{2} \mathrm{O}_{2}$ can be released from various types of cells, including vascular cells $[23,24]$ and has been implicated as an endotheliumderived hyperpolarizing factor exhibiting vasodilator activity [23]. Extraluminal administration of $\mathrm{H}_{2} \mathrm{O}_{2}(1-100 \mu \mathrm{mol} / \mathrm{L})$ elicits concentration-dependent dilation of isolated coronary arterioles in part via an endothelium-dependent mechanism through cyclooxygenase-1-mediated release of $\mathrm{PGE}_{2}$ [25]. $\mathrm{H}_{2} \mathrm{O}_{2}$ can also cause smooth muscle hyperpolarization and lead to vasodilation through the opening of calcium-activated potassium channels [25]. This vasodilatory response appears to play a role in coronary homeostasis by maintaining perfusion during pressure reduction (i.e., autoregulation) [26] and metabolic activation (i.e., functional hyperemia) [27], respectively, in the heart. Interestingly, in disease states, the vasodilator action of $\mathrm{H}_{2} \mathrm{O}_{2}$ appears to compensate for the impaired NO-mediated dilation linking to the uncoupling of $\mathrm{NO}$ synthase with its cofactor tetrahydrobiopterin [28] and to protect ischemia-reperfusion injury in the coronary microcirculation [29]. Recently, in the pig model, we found that the impaired NOmediated vasodilation in collateral-dependent arterioles distal to chronic coronary occlusion was restored by exercise training [30]. The beneficial effect of exercise on coronary arteriolar function was abolished by catalase, suggesting the contribution of $\mathrm{H}_{2} \mathrm{O}_{2}$ in compensating and restoring endothelium-dependent NO-mediated vasomotor function during the adaptation of coronary collateral microvessels to myocardial ischemia [30]. On the other hand, it has been reported that $\mathrm{H}_{2} \mathrm{O}_{2}$ can exert an adverse effect by reducing endothelial release of $\mathrm{NO}$ for vasodilation when the endothelium is exposed to a prolonged (e.g., 60 minutes) elevation of $\mathrm{H}_{2} \mathrm{O}_{2}$ (e.g., $100 \mu \mathrm{mol} / \mathrm{L}$ ) [31]. Interestingly, the dilation mechanisms involving cyclooxygenase, guanylyl cyclase, cytochrome-P450 monooxygenase, and potassium channel activation are not affected by $\mathrm{H}_{2} \mathrm{O}_{2}$ [31] Supplementation of L-arginine or inhibition of arginase restores $\mathrm{H}_{2} \mathrm{O}_{2}$-impaired vasomotor function. Moreover, the adverse effect of $\mathrm{H}_{2} \mathrm{O}_{2}$ can be prevented by inhibiting hydroxyl radical production [31]. It appears that a high intravascular level of $\mathrm{H}_{2} \mathrm{O}_{2}$ selectively impairs endothelium-dependent NO-mediated dilation of coronary microvessels by reducing L-arginine availability through upregulated arginase-I. The formation of hydroxyl radical leading to arginase-I overexpression appears to be responsible for the adverse effect of $\mathrm{H}_{2} \mathrm{O}_{2}$.

Collectively, redox signaling with a low level of $\mathrm{H}_{2} \mathrm{O}_{2}$ released from cardiomyocytes and/or endothelial cells displays an indispensable role in maintaining microcirculatory homeostasis by regulating vasomotor activity in response to physiological challenges. The release of $\mathrm{H}_{2} \mathrm{O}_{2}$ from the vasculature helps to restore vasomotor function by

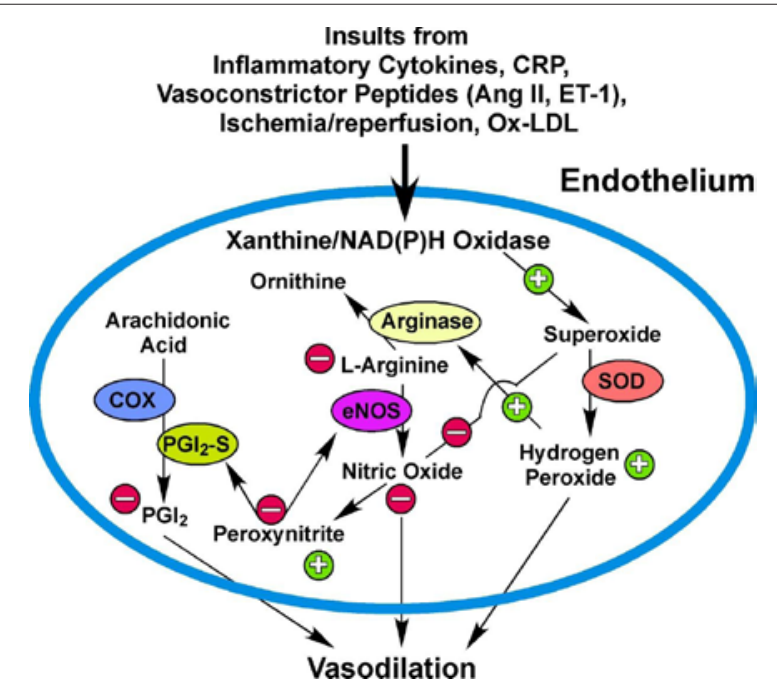

+: enhance/increase/upregulate; -: inhibit/reduce.

Figure 1: Redox modulation of coronary vasomotor function. The low level of superoxide and hydrogen peroxide is essential for maintaining normal homeostasis of the endothelium to exert vasodilation in response to physiological stimulation. The excessive production of superoxide from the activated xanthine oxidase and/or $\mathrm{NAD}(\mathrm{P}) \mathrm{H}$ oxidase by insults from inflammatory cytokines, C-reactive protein (CRP), ischemia/reperfusion, oxidized low-density lipoprotein (Ox-LDL) or vasoconstrictor peptides such as angiotensin II (Ang II) and endothelin-1 (ET-1) scavenges the released nitric oxide and subsequently forms peroxynitrite. The prolonged and elevated production of hydrogen peroxide from superoxide dismutase (SOD) suppresses NO production by upregulating vascular arginase, which limits substrate L-arginine availability to nitric oxide synthase (eNOS). The production of nitric oxide from eNOS and prostacyclin $\left(\mathrm{PGI}_{2}\right.$ ) from cyclooxygenase (COX) and $\mathrm{PGI}_{2}$ synthase $\left(\mathrm{PGI}_{2}-\mathrm{S}\right.$ ) is inhibited by peroxynitrite due to uncoupling of eNOS and nitration of $\mathrm{PGI}_{2}-\mathrm{S}$ (see text for details). These redox events compromise endothelial function and thus augment vascular tone and reduce arteriolar dilation for blood flow recruitment during metabolic activation/stress of the heart. 
compensating for NO deficiency in coronary collateral microvessels adapted to chronic myocardial ischemia with exercise training. Depending upon the disease model and the pathophysiological insult, the excessive and prolonged production of superoxide, via stress kinase-activated $\mathrm{NAD}(\mathrm{P}) \mathrm{H}$ oxidase or xanthine oxidase, and the subsequent exorbitant formation of $\mathrm{H}_{2} \mathrm{O}_{2}$, appear to generate oxidative stress and inflammation, which outweighs the benefits of vasoregulation by impairing endothelial function and possibly exhausting vasodilator reserve (Figure 1). The redox signaling can be a double-edged sword in the microcirculation, which helps tissue survival in one way by improving vasomotor regulation and elicits tissue injury in the other way by causing vascular dysfunction and promoting thrombosis. The status and the balance of redox signaling in the vascular cells and their surrounding parenchymal tissues appear to modulate the homeostasis and vasomotor function of microvessels in health and disease. It is worth noting that the systemic supplementation of antioxidants showed no benefit but instead promoted possible harmful effects in cardiovascular disease prevention or therapy [32-35]. On the other hand, localized manipulation of the redox system and arginase activity in a diseased vasculature might be a useful strategy to improve flow regulation and thus enhance tissue survival.

\section{Acknowledgement}

This work was supported by National Institutes of Health grant HL-48179, HL71761, Retina Research Foundation, Scott \& White Research Foundation (to LK), and EY-018420 (to TWH).

\section{References}

1. Kuo L, Davis MJ, Chilian WM (1992) Endothelial modulation of arteriolar tone. News Physiol Sci 7: 5-9.

2. Hein TW, Kuo L (1999) CAMP-independent dilation of coronary arterioles to adenosine: role of nitric oxide, $\mathrm{G}$ proteins, and $\mathrm{K}_{\mathrm{ATP}}$ channels. Circ Res 85: 634-642

3. Hein TW, Kuo L (1998) LDLs impair vasomotor function of the coronary microcirculation: role of superoxide anions. Circ Res 83: 404-414.

4. Kotecha N, Neild TO (1986) Effects of endothelium-derived relaxing factor on the smooth muscle of the rat tail artery. Clin Exp Pharmacol Physiol 13: 249257

5. Jiang F, Li CG, Rand MJ (1997) Mechanisms of electrical field stimulationinduced vasodilatation in the guinea-pig basilar artery: the role of endothelium. J Auton Pharmacol 17: 71-76.

6. Queisser N, Fazeli G, Schupp N (2010) Superoxide anion and hydrogen peroxide-induced signaling and damage in angiotensin II and aldosterone action. Biol Chem 391: 1265-1279.

7. Schroder E, Eaton P (2008) Hydrogen peroxide as an endogenous mediator and exogenous tool in cardiovascular research: issues and considerations. Curr Opin Pharmacol 8: 153-159.

8. Cai H (2005) Hydrogen peroxide regulation of endothelial function: origins, mechanisms, and consequences. Cardiovasc Res 68: 26-36.

9. Ito N, Ohishi M, Yamamoto K, Tatara Y, Shiota A, et al. (2007) Reninangiotensin inhibition reverses advanced cardiac remodeling in aging spontaneously hypertensive rats. Am J Hypertens 20: 792-799.

10. Xu J, Carretero OA, Liao TD, Peng H, Shesely EG, et al. (2010) Local angiotensin II aggravates cardiac remodeling in hypertension. Am J Physiol Heart Circ Physiol 299: H1328-1338.

11. Heyndrickx GR, Boettcher DH, Vatner SF (1976) Effects of angiotensin, vasopressin, and methoxamine on cardiac function and blood flow distribution in conscious dogs. Am J Physiol 231: 1579-1587.

12. Pörsti I, Hecker M, Bassenge E, Busse R (1993) Dual action of angiotensin
II on coronary resistance in the isolated perfused rabbit heart. Naunyn Schmiedebergs Arch Pharmacol 348: 650-658

13. Sohn HY, Raff U, Hoffmann A, Gloe T, Heermeier K, et al. (2000) Differential role of angiotensin II receptor subtypes on endothelial superoxide formation. Br J Pharmacol 131: 667-672.

14. Zhang C, Hein TW, Wang W, Kuo L (2003) Divergent roles of angiotensin II $\mathrm{AT}$, and $\mathrm{AT}_{2}$ receptors in modulating coronary microvascular function. Circ Res 92: 322-329.

15. Qamirani E, Ren Y, Kuo L, Hein TW (2005) C-reactive protein inhibits endothelium-dependent NO-mediated dilation in coronary arterioles by activating $\mathrm{p} 38$ kinase and $\mathrm{NAD}(\mathrm{P}) \mathrm{H}$ oxidase. Arterioscler Thromb Vasc Biol 25: 995-1001.

16. Nagaoka T, Kuo L, Ren Y, Yoshida A, Hein TW (2008) C-reactive protein inhibits endothelium-dependent nitric oxide-mediated dilation of retina arterioles via enhanced superoxide production. Invest Ophthalmol Vis Sci 49: 2053-2060.

17. Hein TW, Qamirani E, Ren Y, Kuo L (2009) C-reactive protein impairs coronary arteriolar dilation to prostacyclin synthase activation: role of peroxynitrite. J Mol Cell Cardiol 47: 196-202.

18. Zou MH, Shi C, Cohen RA (2002) Oxidation of the zinc-thiolate complex and uncoupling of endothelial nitric oxide synthase by peroxynitrite. J Clin Invest 109: 817-826.

19. Zhang C, Hein TW, Wang W, Ren Y, Shipley RD, et al. (2006) Activation of JNK and xanthine oxidase by TNF- $\alpha$ impairs nitric oxide-mediated dilation of coronary arterioles. J Mol Cell Cardiol 40: 247-257.

20. Zhang C, Xu X, Potter BJ, Wang W, Kuo L, et al. (2006) TNF-a contributes to endothelial dysfunction in ischemia/reperfusion injury. Arterioscler Thromb Vasc Biol 26: 475-480.

21. Hein TH, Zhang C, Wang W, Chang Cl, Thengchaisri N, et al. (2003) Ischemia-reperfusion selectively impairs nitric oxide-mediated dilation in coronary arterioles: counteracting role of arginase. FASEB J 17: 2328-2330.

22. Wang W, Hein TW, Zhang C, Zawieja DC, Liao JC, et al. (2011) Oxidized lowdensity lipoprotein inhibits nitric oxide-mediated coronary arteriolar dilation by up-regulating endothelial arginase I. Microcirculation 18: 36-45.

23. Matoba T, Shimokawa H, Morikawa K, Kubota H, Kunihiro I, et al. (2003) Electron spin resonance detection of hydrogen peroxide as an endotheliumderived hyperpolarizing factor in porcine coronary microvessels. Arterioscler Thromb Vasc Biol 23: 1224-1230.

24. Dikalov SI, Dikalova AE, Bikineyeva AT, Schmidt HH, Harrison DG, et al (2008) Distinct roles of Nox1 and Nox4 in basal and angiotensin II-stimulated superoxide and hydrogen peroxide production. Free Radic Biol Med 45: 1340-1351.

25. Thengchaisri N, Kuo L (2003) Hydrogen peroxide induces endotheliumdependent and -independent coronary arteriolar dilation: role of cyclooxygenase and potassium channels. Am J Physiol Heart Circ Physiol 285: $\mathrm{H} 2255-\mathrm{H} 2263$

26. Yada T, Shimokawa H, Hiramatsu O, Kajita T, Shigeto F, et al. (2003) Hydrogen peroxide, an endogenous endothelium-derived hyperpolarizing factor, plays an important role in coronary autoregulation in vivo. Circulation 107: $1040-1045$.

27. Saitoh S, Kiyooka T, Rocic P, Rogers PA, Zhang C, et al. (2007) Redox dependent coronary metabolic dilation. Am J Physiol Heart Circ Physiol 293: $\mathrm{H} 3720-\mathrm{H} 3725$

28. Katusic ZS (2001) Vascular endothelial dysfunction: does tetrahydrobiopterin play a role? Am J Physiol Heart Circ Physiol 281: H981-H986.

29. Yada T, Shimokawa H, Hiramatsu O, Haruna Y, Morita Y, et al. (2006) Cardioprotective role of endogenous hydrogen peroxide during ischemiareperfusion injury in canine coronary microcirculation in vivo. Am J Physiol Heart Circ Physiol 291: H1138-H1146.

30. Thengchaisri N, Shipley R, Ren Y, Parker J, Kuo L (2007) Exercise training restores coronary arteriolar dilation to NOS activation distal to coronary artery 
occlusion: role of hydrogen peroxide. Arterioscler Thromb Vasc Biol 27: 791798.

31. Thengchaisri N, Hein TW, Wang W, Xu X, Li Z, et al. (2006) Upregulation of arginase by $\mathrm{H}_{2} \mathrm{O}_{2}$ impairs endothelium-dependent nitric oxide-mediated dilation of coronary arterioles. Arterioscler Thromb Vasc Biol 26: 2035-2042.

32. Miller ER 3rd, Pastor-Barriuso R, Dalal D, Riemersma RA, Appel LJ, et al (2005) Meta-analysis: high-dosage vitamin E supplementation may increase all-cause mortality. Ann Intern Med 142: 37-46

33. Bjelakovic G, Nikolova D, Gluud LL, Simonetti RG, Gluud C (2012) Antioxidan supplements for prevention of mortality in healthy participants and patients with various diseases. Cochrane Database Syst Rev 3: CD007176.

34. Tinkel J, Hassanain H, Khouri SJ (2012) Cardiovascular antioxidant therapy: a review of supplements, pharmacotherapies, and mechanisms. Cardiol Rev 20: $77-83$.

35. Lee IM, Cook NR, Gaziano JM, Gordon D, Ridker PM, et al. (2005) Vitamin E in the primary prevention of cardiovascular disease and cancer: the Women's Health Study: a randomized controlled trial. JAMA 294: 56-65.
Author Affiliation

${ }^{1}$ Departments of Systems Biology \& Translational Medicine, Ophthalmology and Surgery, College of Medicine, Texas A\&M Health Science Center, Temple, Texas 76504, USA

Submit your next manuscript and get advantages of SciTechnol submissions

* 50 Journals

* 21 Day rapid review process

* 1000 Editorial team

* 2 Million reader

* More than 5000 facebook"

* Publication immediately after acceptance

* Quality and quick editorial, review processing

Submit your next manuscript at • www.scitechnol.com/submission 